\title{
Transformation of primary human hepatocytes in hepatocellular carcinoma
}

\author{
MAURO MONTALBANO ${ }^{1,2}$, CRISTIANA RASTELLINI ${ }^{1}$, XIAOFU WANG ${ }^{1}$, TIZIANA CORSELLO ${ }^{1,2}$, \\ MAHMOUD A. ELTORKY ${ }^{3}$, RENZA VENTO $^{4,5}$ and LUCA CICALESE ${ }^{1}$ \\ ${ }^{1}$ Department of Surgery, University of Texas Medical Branch, Galveston, TX, USA; ${ }^{2}$ Department of \\ Experimental Biomedicine and Clinical Neurosciences, University of Palermo, Polyclinic, Palermo, Italy; \\ ${ }^{3}$ Department of Pathology, University of Texas Medical Branch, Galveston, TX, USA; ${ }^{4}$ Laboratory of \\ Biochemistry, Department of Biological, Chemical and Pharmaceutical Sciences and Technologies, Polyclinic, \\ University of Palermo, Palermo, Italy; ${ }^{5}$ Institute for Cancer Research and Molecular Medicine and Center \\ of Biotechnology, College of Science and Biotechnology, Temple University, Philadelphia, PA, USA
}

Received June 30, 2015; Accepted July 29, 2015

DOI: 10.3892/ijo.2015.3312

\begin{abstract}
Hepatocellular carcinoma (HCC) is the most common primary liver cancer. Currently, there is limited knowledge of neoplastic transformation of hepatocytes in HCC. In clinical practice, the high rate of HCC local recurrence suggests the presence of different hepatocyte populations within the liver and particularly in the tumor proximity. The present study investigated primary human hepatocyte cultures obtained from liver specimens of patients affected by cirrhosis and $\mathrm{HCC}$, their proliferation and transformation. Liver samples were obtained from seven HCC cirrhotic patients and from three patients with normal liver (NL). Immediately after surgery, cell outgrowth and primary cultures were obtained from the HCC lesion, the cirrhotic tissue proximal $(\mathrm{CP}$, $1-3 \mathrm{~cm})$ and distal $(\mathrm{CD},>5 \mathrm{~cm})$ to the margin of the neoplastic
\end{abstract}

Correspondence to: Dr Luca Cicalese, Department of Surgery, University of Texas Medical Branch, 301 University Boulevard, Galveston, TX 77555-0533, USA

E-mail: lucicale@utmb.edu

Abbreviations: HCC, hepatocellular carcinoma; LTX, liver transplantation; GPC3, Glypican-3; FBS, fetal bovine serum; CP, cirrhotic proximal; $\mathrm{CD}$, cirrhotic distal; NL, normal liver; $\mathrm{PHH}$, primary human hepatocytes; KC, kupffer cells; LEC, liver endothelial cells; CP-Hep, hepatocytes isolated from cirrhotic proximal tissue; CD-Hep, hepatocytes isolated from cirrhotic distal tissue; $\alpha \mathrm{SMA}$, $\alpha$-smooth muscle actin; BSA, bovine serum albumin; HSC, hepatic stellate cell; CK18, cytokeratin 18; CD31 cluster of differentiation 31; CD44, cluster of differentiation 44; CD68, cluster of differentiation 68; CycD1, cyclin D1; PCNA, proliferating cell nuclear antigen; NPC, non-parenchymal cells; Heppar1, hepatocytes paraffin1

Key words: liver cancer transformation, hepatocellular carcinoma, cirrhotic liver, glypican-3, CD44 lesion, or from NL. Cells were kept in culture for 16 weeks. Morphologic analyses were performed and proliferation rate of the different cell populations compared over time. Glypican-3, Heppar1, Arginase1 and CD-44 positivity were tested. The degree of invasiveness of cells acquiring neoplastic characteristics was studied with a Transwell migration assay. We observed that HCC cells maintained their morphology and unmodified neoplastic characteristics when cultured. Cells isolated from $\mathrm{CP}$, showed a progressive morphologic transformation in HCC-like cells accompanied by modification of markers expression with signs of invasiveness. Absence of HCC contamination in the CP isolates was confirmed. In CD samples some of these characteristics were present and at significantly lower levels. With the present study, we are the first to have identified and describe the existence of human hepatocytes near the cancerous lesion that can transform in $\mathrm{HCC}$ in vitro.

\section{Introduction}

Hepatocellular carcinoma (HCC) is the most common primary liver cancer (85-90\%). Age-adjusted HCC incidence rates have doubled over the past two decades. It is estimated that 8,000-11,000 new cases of HCC occur annually in the United States and this number is increasing every year. $\mathrm{HCC}$ is responsible for half million deaths annually $(7.9 \%$ of all cancers) and is the third leading cause of cancer-related mortality worldwide (1-3). Currently, the effective treatments of HCC are liver transplantation (LTX), surgical resection or loco regional ablative therapy (4-6). While surgical treatments also remove some of the cirrhotic tissue surrounding the tumor, the other ablative therapies focus on the destruction of cancerous tissue alone. The current clinical practice requires obtaining at least $1 \mathrm{~cm}$ margin from peri-neoplastic cirrhotic tissue to avoid missing tumor cells or satellite micro-foci in order to obtain a radical oncologic extirpation. Despite the 5 -year disease-free survival rates of $\sim 70 \%$, up to $78 \%$ of local recurrence rate has been reported $(5,6)$. 
Overall, the prognosis for the majority of patients with HCC remains poor due to the limited number of patients that are candidates for surgical intervention or LTX. Poor prognosis is also associated to a high level of tumor invasiveness, frequent intra-hepatic spread, extra hepatic metastasis, and resistance to chemotherapy $(2,3)$. The 1- and 3-year 'intention-to-treat' survival rates are 85 and $62 \%$, for resection, and 84 and $69 \%$ for LTX, respectively (5). However, for loco-regional therapy with ablation, the corresponding recurrence-free survival rates reported are 68.7 and 59.2\%, respectively (7). These variations could be secondary to removal vs. ablation of neoplastic tissue and consequent different micro-environment modifications of the residual liver tissue. Alternatively, this could result from the removal of larger portions or the entire peri-neoplastic cirrhotic tissue potentially more prone to future cancer modification.

At the present time, no scientific data exist on the characteristics of the liver tissue surrounding HCC lesions. In the current clinical practice, the resection margin is evaluated with standard histology to rule out the presence of neoplastic cells. However, liver cells adjacent to the neoplastic lesion could be in a pre-cancerous state even if morphologically non-neoplastic and could be dispersed for an unidentified distance.

Since the recurrence of HCC occurs typically in the area of resection or peri-ablative area, we hypothesize that, in the cirrhotic liver, HCC develops in a specific location where there are optimal micro-environmental conditions. To test this hypothesis, we studied liver samples from seven patients with cirrhosis secondary to viral hepatitis and undergoing liver resection for HCC. Namely, samples were obtained from: HCC lesions and from locations proximal $(1-3 \mathrm{~cm})$ and distal $(>5 \mathrm{~cm}$ or contra-lateral lobe) to the margin of the HCC lesion. From these samples, cell outgrowths were obtained and primary cultures were developed and followed for 16 weeks to evaluate morphological and phenotypic characteristics.

Most data available from the literature describe characteristics of HCC cells obtained from immortalized cell lines and do not offer insights on the dynamic evolution of HCC primary cell cultures (8). To the best of our knowledge, no studies are available at this time describing the characteristics and temporal dynamic transformation in HCC of non-neoplastic hepatocytes obtained from cirrhotic livers at incremental distance from tumor lesions.

\section{Materials and methods}

Patients and sample collection. Patients were enrolled following Institutional Review Board approval and informed consent in accordance with the UTMB institutional policies. Samples were obtained from patients with liver cirrhosis and HCC undergoing liver resection. Characteristics of the patients recruited are summarized in Table I. Liver samples were also obtained from three patients without cirrhosis or HCC and used as normal liver (NL) control. Fresh tissue samples were obtained at the time of surgery, immediately placed in cold $\left(4^{\circ} \mathrm{C}\right)$ sterile saline solution and transported to the cell isolation laboratory. Histopathological evaluation of the tissue samples was performed using standard hematoxylin and eosin (H\&E) staining. Sections were examined by a pathologist to confirm
Table I. Demographic and pathological characteristics of HCC patients $(\mathrm{N}=7)$.

\begin{tabular}{lc}
\hline Characteristics & Data \\
\hline Mean age (year range) & $57(48-68)$ \\
Gender & \\
Male & 6 \\
Female & 1 \\
Ethnicity & \\
Black & 2 \\
Hispanic & 3 \\
Caucasian/White & 2 \\
HCV positivity & 7 \\
Mean tumor size (range in cm) & $1.55(1-2.5)$
\end{tabular}

diagnosis of HCC and to rule out neoplastic contamination in cirrhotic liver samples utilized as cirrhotic proximal (CP) and cirrhotic distal (CD) for the present study. Additional samples from HCC, NL and cirrhotic liver tissues (CP and $\mathrm{CD}$ ) were individually placed in RNAlater Stabilization reagent (Qiagen) and immediately cryopreserved at $-160^{\circ} \mathrm{C}$.

Immunohistochemistry analysis. Specimens were fixed in $10 \%$ neutral formalin and embedded in paraffin. Tissue sections were cut at 3-5 $\mu \mathrm{m}$ and mounted on positively charged slides. Sections were treated with antigen retrieval to facilitate antibody binding to antigen and incubated in the Black and Decker vegetable steamer for $20 \mathrm{~min}$ in target retrieval solution (Dako Corp., Carpinteria, CA, USA; cat. \#S1699) preheated to $99^{\circ} \mathrm{C}$. When removed and cooled down, the slides were then rinsed three times with distilled water and placed into a container of Tris-buffered saline with Tween-20 (Signet Pathology Systems, Inc., Dedham, MA, USA; cat. \#2380). Both avidin and biotin (blocking kit; Vector Laboratories Inc., Burlingame, CA, USA; cat. \#SP2001) were diluted in Antibody Diluent (Dako) at a ratio of $1 \mathrm{ml}$ avidin or biotin to $5 \mathrm{ml}$ diluent. Diluted avidin was applied to sections and incubated for $7 \mathrm{~min}$. The primary antibody was diluted to specific concentrations in the biotin solution and applied for the specific amount of time recommended by the company. Sections were then incubated in LSAB2, universal secondary antibody (Dako) for $15 \mathrm{~min}$, followed by Chromagen liquid DAB (Dako) application for $5 \mathrm{~min}$. Slides were taken off the Autostainer and rinsed in distilled water, manually counterstained with Harris's haematoxylin (Thermo Fisher Scientific) for $1 \mathrm{~min}$, rinsed in distilled water followed by $0.25 \%$ ammonia water and rinsed in distilled water again. Following dehydration through graded series of alcohols, they were cleared in four changes of xylene and coverslipped with cover glass. Glypican-3 (GPC3), Heppar1 and Arginase1 were analyzed by immunohistochemistry $(9,10)$. The antibodies and concentrations used were GPC3 (1:400; Abcam Inc., Cambridge, MA, USA; \#ab129381), Heppar1 (1:50; Dako Clone OCH1E5 \#M7158) and Arginasel (1:400; Abcam; \#ab117989) for HCC cells detection. 
Isolation and in vitro culture of primary $H C C, C P, C D$ and NL cells. Tissue specimens obtained as described above, were washed in PBS and processed within $2 \mathrm{~h}$ from surgical resection. Samples were washed with physiologic solution, minced with fine sterile scissors and scalpel into fragments of $\sim 1 \mathrm{~mm}^{3}$. Cells were immediately isolated from the $\mathrm{HCC}$ lesion, and from cirrhotic tissue proximal $(\mathrm{CP}, 1-3 \mathrm{~cm})$ and distal $(\mathrm{CD},>5 \mathrm{~cm}$ or contra-lateral lobe) to the HCC. The cell isolation procedure was performed with modifications from methods described by Tomuleasa et al (11). Briefly, the $1 \mathrm{~mm}^{3}$ fragments of tissue were incubated for $3 \mathrm{~h}$ with fetal bovine serum (FBS) HyClone (Thermo Fisher Scientific). FBS was then replaced by complete RPMI-1640 medium with $10 \%$ FBS, $1 \%$ of antibiotics (Corning-Cellgro, Manassas, VA, USA) and amino acids [Sigma-Aldrich; MEM Non-essential amino acid solution (x100) \#M7145] and incubated for $24 \mathrm{~h}$. Every $48 \mathrm{~h}$ cells were then washed with $2 \mathrm{ml}$ of RPMI-1640 complete medium. After 3 weeks a monolayer of primary cells around the explants was observed. Cells were detached using $1 \mathrm{X}$ trypsin/EDTA (Corning-Cellgro), re-plated and maintained in culture at $37^{\circ} \mathrm{C}$ and $5 \% \mathrm{CO}_{2}$.

$C P$ and CD hepatocytes growth. Hepatocytes isolated from $\mathrm{CP}$ and $\mathrm{CD}$ tissue (CP-Hep and CD-Hep) were incubated from time zero to sixteen weeks and their growth was compared. To conduct this experiment, four series of multiwells (I, II, III and IV), each containing $2 \times 10^{5}$ cells of either CP-Hep or CD-Hep, were prepared (time zero), with each series performed in triplicate. Samples were incubated in the culture conditions previously described for up to sixteen weeks. Starting from week ten, cells from the four series of the two cell types were detached at 2 weeks intervals with 1X Trypsin EDTA and counted. Namely, for each cell type, the series corresponded to: I, from time zero to week ten; II, from time zero to week twelve; III, from time zero to week fourteen and IV, from time zero to week sixteen. The number of cells obtained for each time-point was employed to produce a graph describing the growth of CP-Hep and CD-Hep, as reported in the results. Moreover, when at the indicated time-points, cells were detached and counted. Aliquots of $2 \times 10^{5}$ cells from each series were reseeded in new multiwells, cultured in RPMI-1640 10\% FBS for the following 2 weeks and then detached and counted. Results obtained were used to produce a histogram describing the growth rate of CP-Hep and CD-Hep from the tenth to the sixteenth week.

Immunofluorescence staining. Cells were fixed with $3.7 \%$ formaldehyde (Sigma-Aldrich) for $10 \mathrm{~min}$ at room temperature (RT) and permeabilized with $0.1 \%$ Triton X-100 (Sigma-Aldrich) in PBS for $5 \mathrm{~min}$. Cells were then rinsed and covered with PBS blocking buffer (1\% BSA in PBS) for $30 \mathrm{~min}$ at $37^{\circ} \mathrm{C}$ to minimize non-specific adsorption of the antibodies to the coverslips. After washing with PBS, cells were incubated with the primary antibodies (anti-GPC3 and anti- $\alpha$-SMA; Abcam; diluted in PBS $+1 \%$ BSA $+0.05 \%$ $\mathrm{NaN}_{3}$ ) at $4^{\circ} \mathrm{C}$, overnight. Preparations were washed three time with PBS and incubated for $1 \mathrm{~h}$ at room temperature with secondary antibodies, either Alexa Fluor 488 (Abcam; \#150113) or Alexa Fluor 596 (Abcam; \#150080) diluted $1: 1,000$ in $1 \% \mathrm{BSA}+0.05 \% \mathrm{NaN}_{3}$. Nuclei were counter- stained with $2.5 \mu \mathrm{g} / \mathrm{ml}$ Hoechst 33342 (Life Technologies NucBlue ${ }^{\circledR}$ Live ReadyProbes ${ }^{\circledR}$ reagent; Life Technologies, Grand Island, NY, USA; 14072, \#37605) for 15-20 min. Following three washes with PBS, cells were examined on Olympus BX51 optic microscope equipped with fluorescence and suitable filters for Alexa Fluor 488, Alexa Fluor 596 and DAPI detection; images were captured and photographed using a computer-imaging system (PictureFrame ${ }^{\mathrm{TM}}$ ). Primary antibodies used for immunofluorescence staining included: Albumin [1:500; Santa Cruz Biotechnology, Santa Cruz, CA, USA; (F-10) sc-271605], cytokeratin 18 (CK18, 1:100; Abcam; ab9217), Heppar1 (1:100; Dako; M7158), CD68 (1:500; Santa Cruz Biotechnology; sc-393951), CD31 (1:500; Santa Cruz Biotechnology; sc-376764) and $\beta$-catenin (1:250; Abcam; ab32572).

Red-oil staining. Red-oil stain was used to identify quiescent hepatic stellate cells (HSCs) (26). Cells were plated in 35-mm wells. After $48 \mathrm{~h}$, culture medium was removed and cells were washed with $2 \mathrm{ml}$ of PBS. Pelleted cells were fixed in $2 \mathrm{ml}$ of $10 \%$ formalin and incubated at RT for $1 \mathrm{~h}$. Formalin was removed and cells were washed with $2 \mathrm{ml}$ of $\mathrm{ddH}_{2} \mathrm{O}$ twice and incubated in $2 \mathrm{ml}$ of $60 \%$ isopropanol for $5 \mathrm{~min}$ at RT. Cells were let dry completely at RT and $1 \mathrm{ml}$ of undiluted Red-oil working solution was added followed by incubation at RT for $10 \mathrm{~min}$. Red-oil solution was removed and the sample was washed with $\mathrm{ddH}_{2} \mathrm{O}$. Images were acquired using optic microscopy.

Protein extraction and western blot analysis. Western blotting was performed on whole cell lysates to detect GPC3, CD44, CD44v6, $\alpha$-SMA, PCNA and cyclin D1 (CycD1) expression. Cells were cultured and harvested before confluence. Cells $\left(1 \times 10^{7}\right)$ were lysed using a modified RIPA buffer [150 mM NaCl, $25 \mathrm{mM}$ Tris (pH 7.4), 1 mM EDTA, $1 \mathrm{mM}$ EGTA, 2 mM Na $\mathrm{VO}_{4}, 10 \mathrm{mM} \mathrm{NaF}, 1 \% \mathrm{NP} 40,10 \%$ glycerol, aprotinin $(10 \mathrm{mg} / \mathrm{ml})$ and leupeptin $(10 \mathrm{mg} / \mathrm{ml})]$. Supernatant was collected and quantified by a BCA protein assay (Pierce, Rockford, IL, USA). Equal amounts of proteins were separated by SDS-PAGE and transferred to nitrocellulose membrane (LI-COR Biosciences; \#926-31090), which was blocked using $5 \%$ non-fat dry milk in Tris-buffered saline with Tween-20 (Blocking buffer; LI-COR Biosciences, Lincoln, NE, USA; \#927-40040). The membrane was incubated overnight at $4^{\circ} \mathrm{C}$ with the primary antibodies listed above. After incubation, the membrane was washed 3 times with PBST and then rinsed and incubated for $1 \mathrm{~h}$ at RT in appropriate anti-mouse or anti-rabbit IRDye 680-800 secondary antibodies (LI-COR Biosciences). The membrane was rinsed, developed with Odyssey Imaging Systems LI-COR and specific protein bands were detected with Image Studio software (version 4.0.21; Li-COR Biosciences). Actin and GAPDH served as loading controls.

Flow cytometric analysis. CP-Hep and CD-Hep from the fourth and the sixteenth week of incubation were detached using Accutase (StemPro ${ }^{\circledR}$ Accutase ${ }^{\circledR}$ Cell Dissociation reagent; Life Technologies; \#A11105-01) in PBS, counted and washed in PBS at $4^{\circ} \mathrm{C}$. At least $5 \times 10^{5}$ cells (in $500 \mu \mathrm{l}$ PBS) were incubated with primary monoclonal antibodies $\left(4^{\circ} \mathrm{C}\right.$ for $30 \mathrm{~min}$ in the dark). The primary antibodies used were: mouse anti-human 
GPC3 9C2 non-conjugated (1/200; Abcam), rabbit anti-human CD44-EPR1013Y non-conjugated (1/30; Abcam). Following subsequent washing in PBS for indirect labelling, cells were incubated with a compatible secondary antibody (Alexa Fluor 488 or 594; 1:2,000; Abcam). After PBS wash, the labelled cells were analyzed by flow cytometer using BD LSRFortessa cell analyzer (BD Biosciences) and BD FACSDiva software. At least of $5 \times 10^{5}$ cells/sample were analyzed, and data were stored in list mode file. The expression of cell markers was determined by comparison with control cells labeled only with secondary antibodies.

Transwell migration/invasion assay. The Transwell 24-well filters (Corning-Cellgro) with $8.0 \mu \mathrm{m}$ pores were used for the migration or invasion assay according to the manufacturer's protocol. Briefly, Transwell membranes were coated with $80 \mu \mathrm{l}$ of ECM (Sigma-Aldrich) at a final concentration of $0.1 \mathrm{mg} / \mathrm{ml}$ and dried. Cells $\left(5 \times 10^{4}\right)$ were placed in $100 \mu \mathrm{l}$ with serum-free RPMI-1640 medium (Corning-Cellgro), added to the upper chamber triplicate wells and allowed to migrate through ECM overnight at $37^{\circ} \mathrm{C}$ with $5 \% \mathrm{CO}_{2}$ in a humidified incubator. The lower compartment of the Transwell chamber was filled with $600 \mu \mathrm{l}$ of RPMI-1640 containing 10\% of FBS. After incubation for $24 \mathrm{~h}$ the medium was changed in both upper and lower compartments and at 48,72 and $96 \mathrm{~h}$ cells were removed from the upper surface of the filter using a cotton swab. Cells were fixed with $95 \%$ ethanol and stained using Giemsa (1:50 for $15 \mathrm{~min}$ at RT). The migrated cells present on the lower surface of the filter were analyzed, photographed with an optic microscope (Nikon Eclipse TS100) and counted. The experiment was repeated three times per sample.

Organoids generation and culture. CP and CD tissues were washed three times with PBS. Using sterile scalpel samples were dissociated into $1-\mathrm{mm}^{3}$ fragments and suspended in $0.5 \mathrm{ml}$ RPMI-1640 medium. Cells were washed twice, seeded in Matrigel (BD Biosciences) in a 1:2 ratio and $100 \mu \mathrm{l}$ of the solution was placed on coverslips. The gel solidified at $37^{\circ} \mathrm{C}$ for $30 \mathrm{~min}$ and was overlaid with RPMI-1640 medium with $10 \%$ of FBS. Organoids were evidenced with Giemsa staining. Their images were acquired at 48, 72 and $96 \mathrm{~h}$ after plating using optic microscope Nikon Eclipse TS100.

Statistical analysis. All the presented results were obtained from experiments repeated in triplicate for each sample obtained from each patient. Samples from seven different patients were used in each experiment. All group data are presented as mean \pm standard deviation of the mean (SD) and statistical analyses were calculated using IBM, SPSS v.20 software. Parametric 2-tail Student's t-test for statistical validation was used. P-value was considered statistically significant when $<0.05$.

\section{Results}

Expression of HCC markers: GPC3, Arginasel and Hepparl. Initially, each specimen ( $\mathrm{NL}, \mathrm{CD}, \mathrm{CP}$ and $\mathrm{HCC}$ ) used to obtain primary cultures was evaluated for GPC3, Arginase1, and Hepparl expression. Immunohistochemistry confirmed, as expected $(12,13)$ expression of GPC3 and overexpression of
Arginase1 and Happar1 in HCC (Fig. 1D, H and L), whereas it showed a very low background expression for GPC3 and Arginase1 in NL tissue (Fig. 1A, E and I) and in cirrhotic tissues (CD and CP) (Fig. 1B, C, F and G). Happar1 showed a very low background expression in NL tissue (Fig. 1I), whereas in cirrhotic tissues (CD and $\mathrm{CP}$ ) its background expression was more evident, although significantly lower than in HCC (Fig. 1J and K). In Fig. 1M-P, H\&E staining confirmed the neoplastic nature of HCC samples and the absence of cancer cells in NL, CD and CP specimens. Histologic examination of the specimens by a pathologist (blinded to the diagnosis) supported the absence of HCC in cirrhotic specimens (CP, CD and NL) utilized to obtain the primary hepatocytes cultures performed.

Morphological observations. Primary cultures of cells obtained from CP and CD evidenced typical histologic features of cirrhotic tissue with canonic cubic shaped hepatocytes and non-parenchymal cells (NPC) (Fig. 2A). At $24 \mathrm{~h}$ after plating cirrhotic specimens, adherent cells were observed (data not shown). The number of cells adherent to the wells increased progressively and, at 4 week, it was possible to distinguish specific cell types. At 4 weeks (5 passages) cells manifested a change in morphological characteristics: CP-Hep and CD-Hep lost their classic cubical shape and acquired fibroblastic/mesenchymal-like phenotype, increased their number with CP-Hep reaching an overall appearance similar to that of HCC. Instead, CD-Hep markedly increased their size with only a minor increase in their number. Furthermore, at 10 weeks, CP-Hep started to aggregate in clusters resembling those observed in HCC. In CD-Hep these aggregates were not visible. All these modifications, illustrated in Fig. 2A, were maintained over time (16 weeks).

Characterization of $\mathrm{PHH}$ cultures. For the identification of primary human hepatocytes $(\mathrm{PHH})$ as well as the different non-parenchymal cells (NPC) and for determination of their purity, the cells isolated were investigated for cell type-specific markers by immunofluorescence staining. Positively stained cells were counted in relation to the total cell number of cells positive for Hoechst 33342. PHH were identified by their cubical shape and the presence of multi-nucleated cells (biand tri-nucleated cells) (Fig. 2A and B). Those cells stained positive for the hepatocytes markers: Albumin, Heppar1 and CK18 (14) (Fig. 2B) at 16 weeks and showed a purity of $93.5 \pm 2.4,94.0 \pm 3.5$ and $92.4 \pm 2.1 \%$, respectively. To exclude the presence of Kupffer cells (KC) and liver endothelial cells (LEC) in hepatocytes cultures, immunofluorescent staining were performed and no immunoreactivity was observed with macrophage-specific surface protein and LEC markers, respectively CD68 and CD31 (Fig. 2B). In addition, classic fenestrations of LEC in cultures were not observed. While $\beta$-catenin is normally not expressed in liver NPC or fibroblasts and is present in hepatocytes (15), in our culture it was expressed in $96 \pm 2.0 \%$ of cells confirming that the majority in the culture were hepatocytes. This expression was more evident in HCC (16) compared to CP-Hep and CD-Hep (Fig. 2B). Table II summarizes the antibodies characteristics used to detect hepatocyte specific antigens by immunofluorescence. 

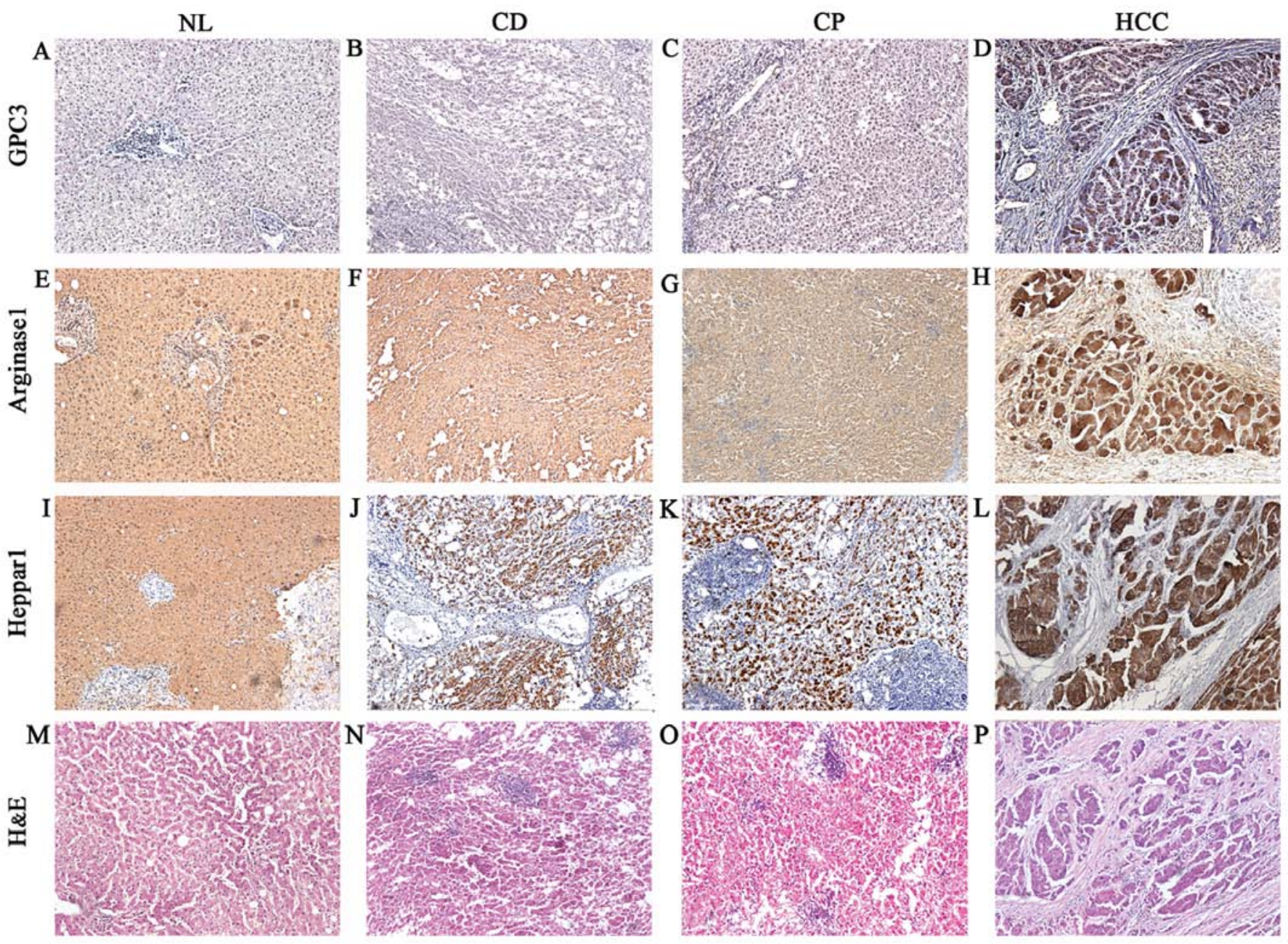

Figure 1. Representative immunohistochemical staining patterns of NL, CD, CP and HCC tissue utilized for cell isolation. GPC3 is absent in NL (A) CD (B) and $\mathrm{CP}(\mathrm{C})$ while is markedly expressed in HCC (D). Arginasel and Hepparl showed overexpression in $\mathrm{HCC}(\mathrm{H}$ and L) compared to NL (E and I) CD (F and J) and $\mathrm{CP}(\mathrm{G}$ and $\mathrm{K})$. Hematoxylin and eosin $(\mathrm{H} \& \mathrm{E})$ stained sections are shown (M-P) (image magnification, $\mathrm{x} 100)$.

Table II. Primary antibodies for immunofluorescence staining of human hepatocytes.

\begin{tabular}{lllcccc}
\hline Antibody & Type & Species & Reactivity & Manufacturer & Dilution & Marker \\
\hline Albumin & Monoclonal & Mouse & Human & Santa Cruz Biotechnology & $1: 500$ & PHH \\
CK18 & Monoclonal & Mouse & Human & Abcam & $1: 100$ & PHH \\
Heppar1 & Monoclonal & Mouse & Human & Dako & $1: 100$ & PHH \\
CD68 & Monoclonal & Mouse & Human & Santa Cruz Biotechnology & $1: 500$ & KC \\
CD31 & Monoclonal & Mouse & Human & Santa Cruz Biotechnology & $1: 500$ & LEC \\
$\beta$-catenin & Monoclonal & Rabbit & Human & Abcam & $1: 250$ & PHH \\
\hline
\end{tabular}

Comparative analysis of cell growth curves between CP-Hep and CD-Hep. As described in Materials and methods, cell growth was evaluated by plating $2.5 \times 10^{5}$ cells of $\mathrm{CP}$ - and CD-Hep in culture medium (time zero). Cells were allowed to grow for established time periods (12, 14 and 16 weeks) at which cultures were stopped and cells counted. Fig. 3A (left panel) shows a progressive increase with sharp rise of growth for CP-Hep, whereas CD-Hep growth rate was gradually reduced, so that at sixteen weeks CD-Hep was $74 \%$ of

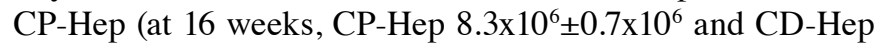

$\left.4.4 \times 10^{6} \pm 0.4 \times 10^{6}\right)$. This confirms the microscopic evidence of the lower cellularity of CD-Hep compared to CP-Hep at 16 weeks as shown in Fig. 2A. Fig. 3A (right panel) also shows a different growth rate for the two cell types (CP-Hep and CD-Hep), acquired over time. Results demonstrate that $\mathrm{CP}-\mathrm{Hep}$ grew at a progressively higher rate as compared to CD-Hep. To confirm cell growth pattern, we evaluated protein levels of PCNA (at 0, 4 and 16 weeks) and CycD1 (at 4 and 16 weeks), markers of DNA replication and cell cycle progression, respectively. Fig. 3B shows that both proteins increase 
A
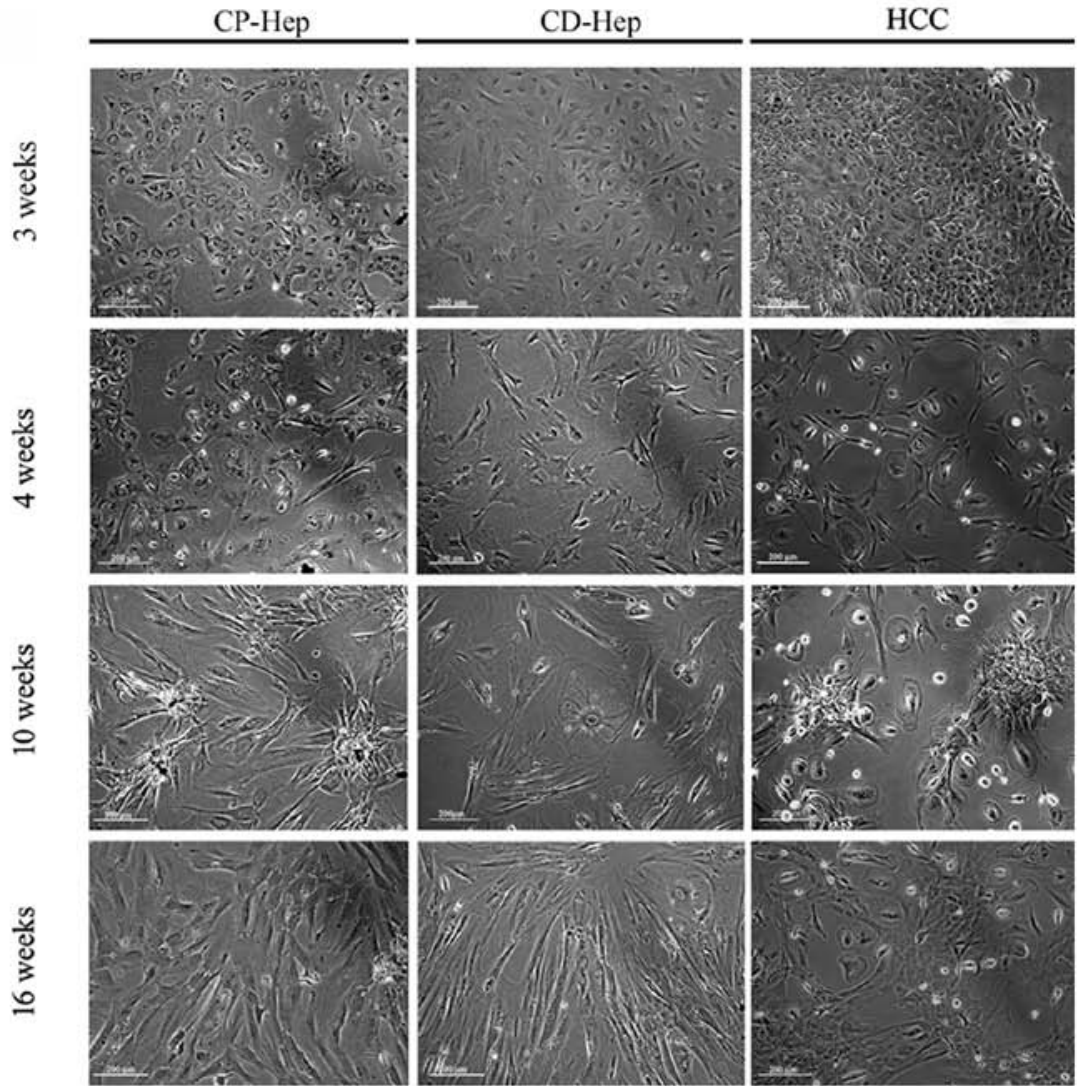

B

CD-Hep

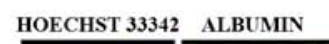

MERGE
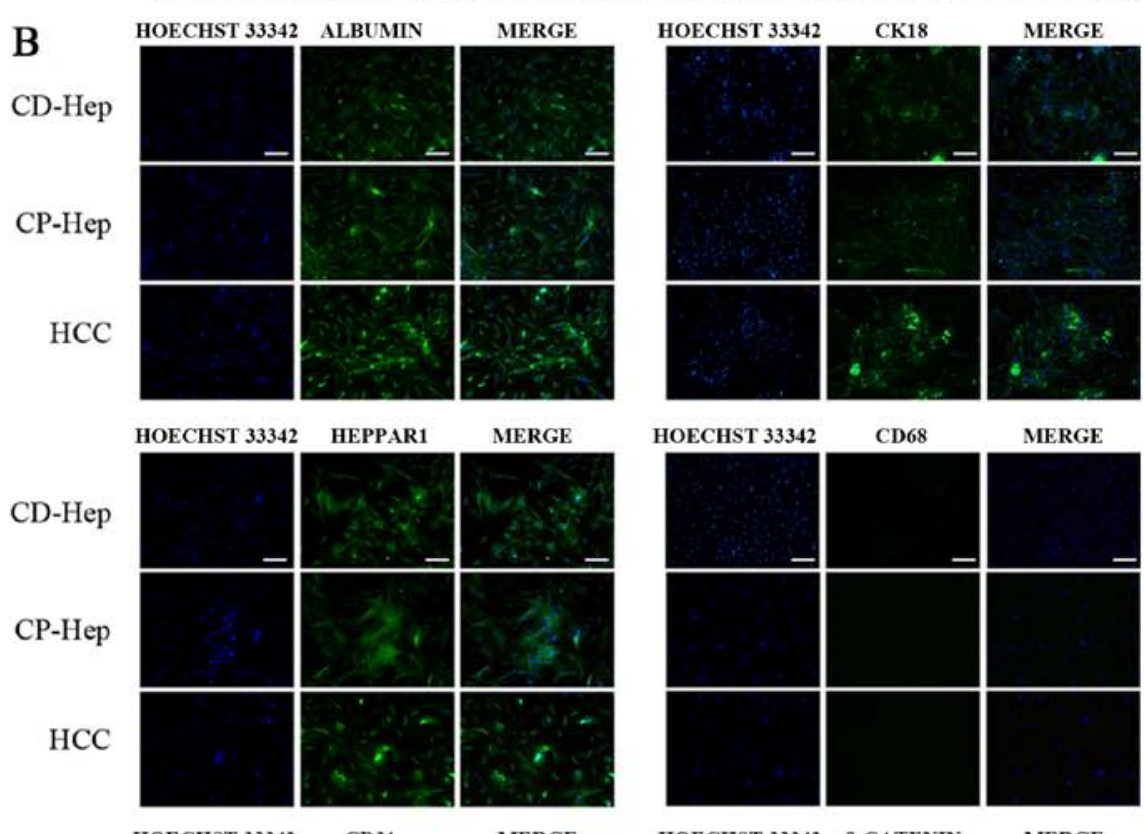

MERGE
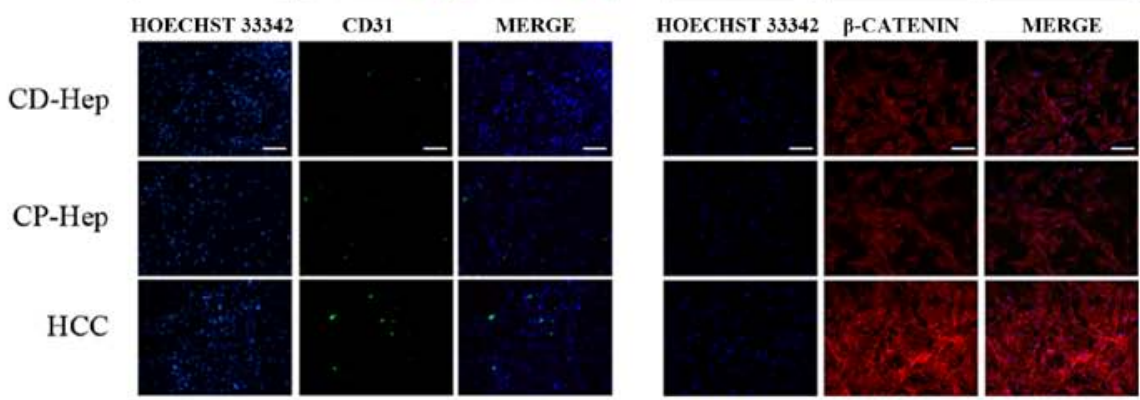

Figure 2. Morphological features of cultured cells obtained from CP, CD and HCC. (A) Cells in primary culture at 3, 4, 10 and 16 weeks. Morphological modifications are evident and maintained over time (16 weeks). CP cells became spindle like, started to aggregate in clusters and increased their proliferation similarly to HCC. CD cells increased in sizes and diminished their proliferation (image magnification, x100; white bar, 200 $\mu \mathrm{m}$ ). (B) Immunofluorescence of hepatocytes markers: Albumin, Heppar1, CK18 in CD-Hep, CP-Hep and HCC, no immunoreactivity for CD68 (macrophage marker) and CD31 (liver endothelial cells), $\beta$-catenin immunofluorescence was positive in all cell cultures that was stronger in HCC compared to CP- and CD-Hep. White bar, $100 \mu \mathrm{m}$. 

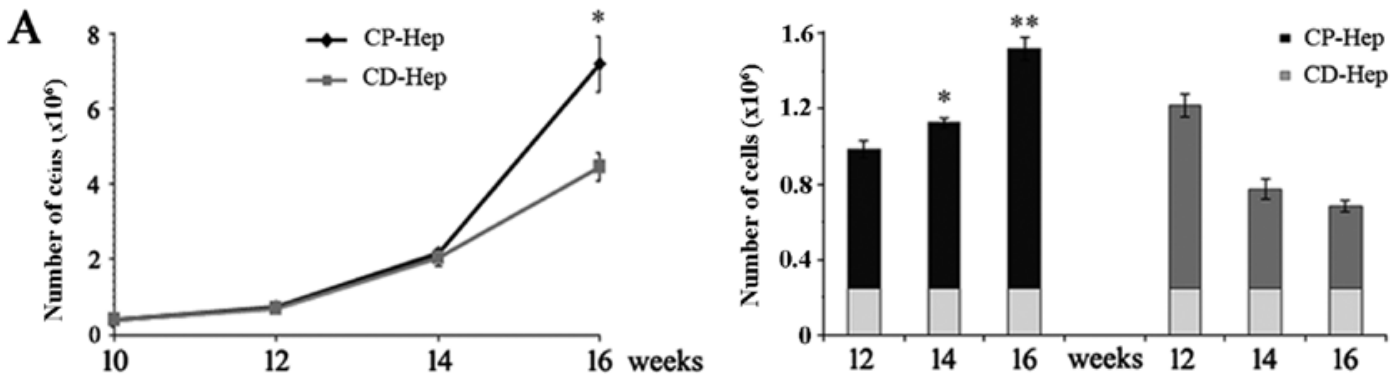

B
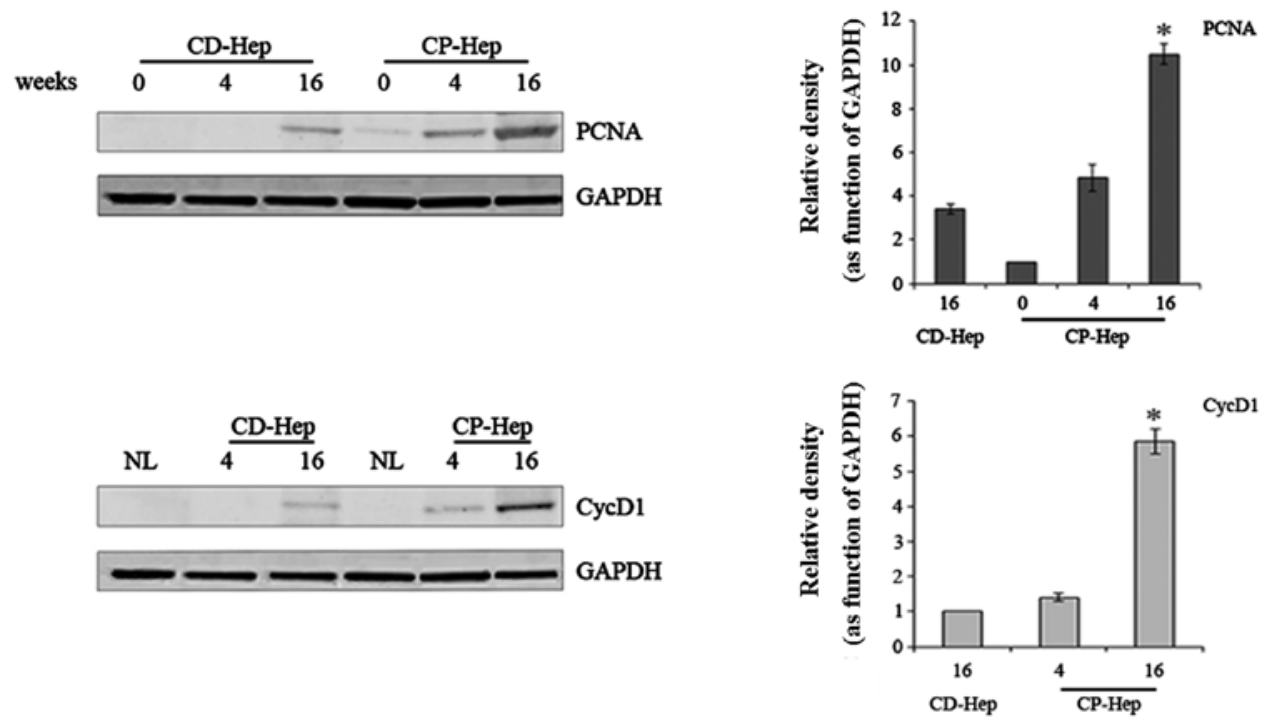

C
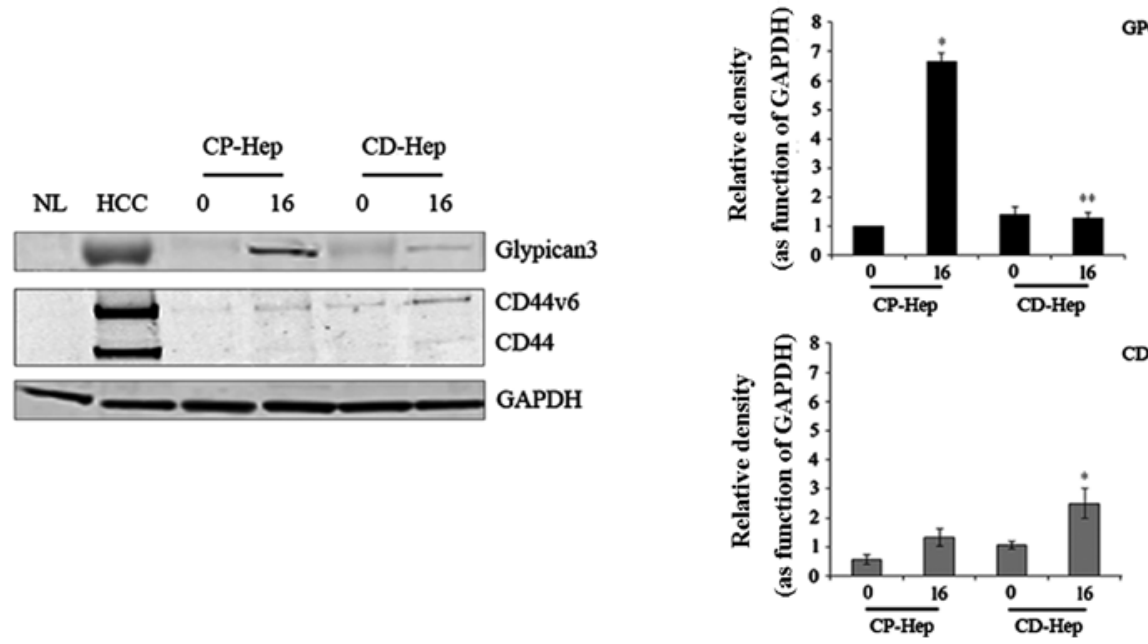

Figure 3. Proliferation and expression of specific HCC markers. (A, left panel). Proliferation rate of CP- and CD-Hep from 0 to 16 weeks $(\mathrm{mean} \pm \mathrm{SD}$, $\mathrm{P}=0.003)$ (A, right panel). Schematic representation of CP- and CD-Hep growth rate. Test performed on $2 \times 10^{5}$ cells samples (shown as light grey bar at the bottom). Proliferation measured at 12, 14 and 16 weeks of culture (CP-Hep vs. CD-Hep, mean $\pm \mathrm{SD}$; NS at $12,{ }^{*} \mathrm{P}=0.007$ at 14 and ${ }^{* *} \mathrm{P}=0.003$ at 16 weeks). (B) Proliferation activity of CP-Hep was evident earlier and more markedly than in CD-Hep when measured by PCNA and CycD1 expression (markers of DNA replication and cell cycle progression). (CP-Hep vs. CD-Hep at 16 weeks, mean $\pm \mathrm{SD}$; PCNA ${ }^{*} \mathrm{P}=0.001$; CycD1 ${ }^{*} \mathrm{P}=0.002$ ). (C) Western blot analysis showed a strong increment of expression for GPC 3 in CP-Hep from 0 to 16 weeks (mean $\pm \mathrm{SD}$; $\mathrm{P}=0.0001$ ). When compared to CD-Hep at 16 weeks, GCP3 was significantly higher in CP-Hep ( $\left.{ }^{* *} \mathrm{P}=0.001\right)$. CD44 and CD44v6 expression was only slightly increased over time in both CP-Hep and CD-Hep with a higher increment in CD-Hep for $\mathrm{CD} 44 \mathrm{v} 6$ at 16 weeks $\left({ }^{*} \mathrm{P}=0.01\right)$.

in expression in CP-Hep earlier and more markedly than in CD-Hep confirming the higher proliferation activity of CP-Hep.

Expression of GPC3, CD44 and CD44v6. Fig. 3C illustrates western blot analyses of specific markers of HCC, namely GPC3, CD44 and CD44v6. GPC3, a specific HCC prolifera- tion marker $(17,18)$ is highly expressed in $\mathrm{HCC}$ cells, while it is absent in NL cells. In HCC, GPC3 appears as a broad smeared band. This could represent a different degree of glycosylation of GPC 3 with a consequent wider range of molecular weight, as described in literature (19-21). Fig. 3 also shows that at time zero CP-Hep and CD-Hep express a low-density smeared band of GPC3. However, at sixteen weeks, this band became more 

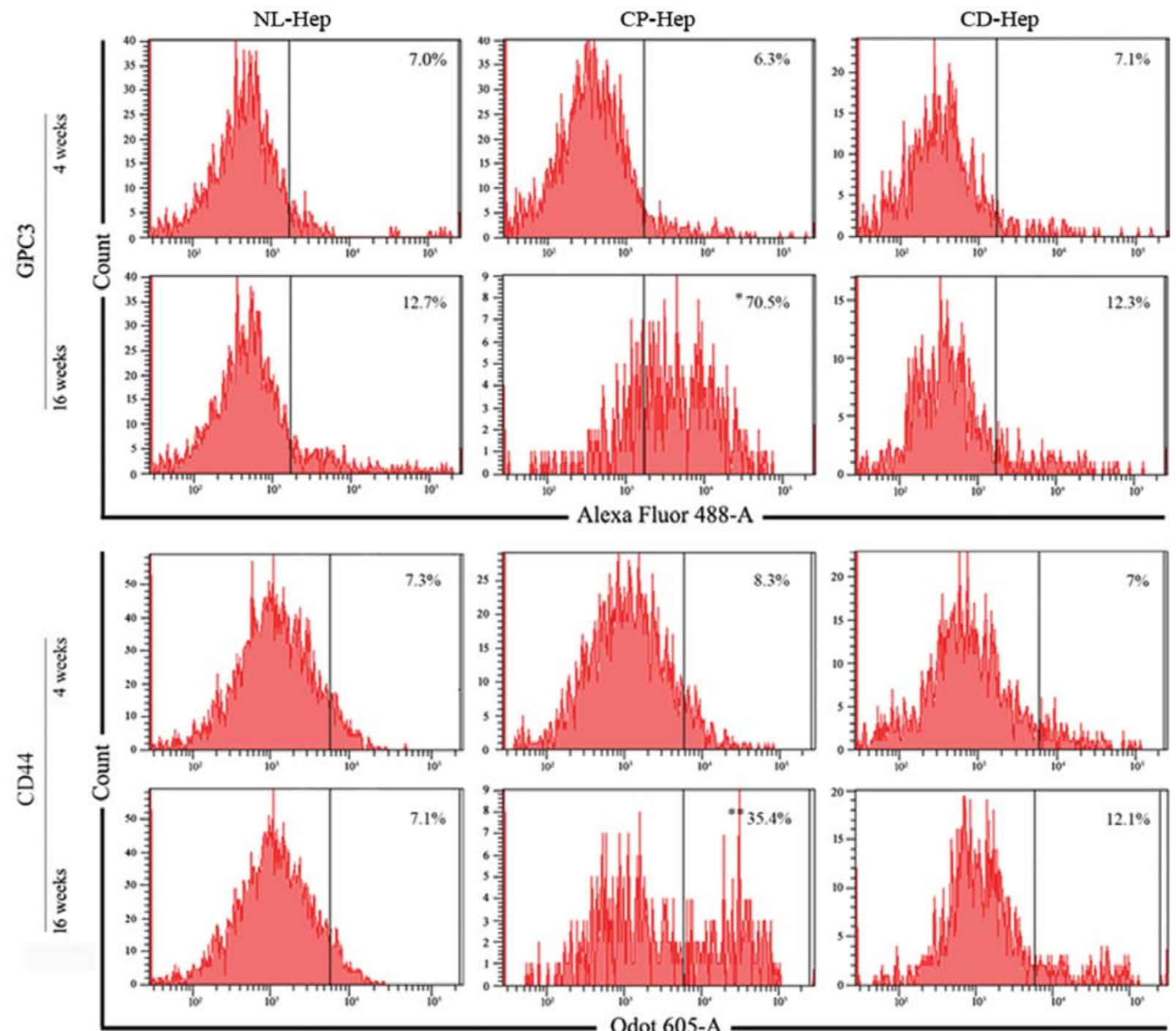

Figure 4. Cytofluorometric analysis of GPC 3 and CD44. Percentage of GPC3 and CD44 positive cells at 4 weeks compared to 16 weeks of culture. The number of positive cells detected was markedly higher in CP-Hep (GPC3 from 6.3 to $70.5 \%{ }^{*} \mathrm{P}=0.0001$ and $\mathrm{CD} 44$ from 8.3 to $35.4 \%{ }^{* *} \mathrm{P}=0.001$ ) compared to $\mathrm{CD}-\mathrm{Hep}$ (GPC3 from 7.1 to $12.3 \%$; and CD44 from 7 to $12.1 \%$ ).

prominent and compact, with levels that were much higher in CP-Hep than in CD-Hep. High expression of CD44 and its isoform CD44v6, both specific markers of liver cancer cells (22-25), were confirmed in HCC, while they were absent in NL samples. In CP and CD samples the CD44 and its isoform CD44v6 showed very low levels at time zero with a small increment at 16 weeks.

Flow cytometry evaluation of GPC3 and CD44 markers in CP-Hep and CD-Hep. GPC3 and CD44 levels were evaluated by cytofluorometry at early and advanced stages of culture (4 and 16 weeks), in NL-, CP- and CD-Hep. At 4 weeks the percentage of cells expressing these markers was very similar in the three cell types (GPC3, NL-Hep 7.0\%, CP-Hep 6.3\%, CD-Hep 7.1\%; CD44, NL-Hep 7.3\%, CP-Hep 8.3\%, and CD-Hep 7\%). However, when measured at 16 weeks, the number of cells expressing GPC3 and CD44 appeared markedly increased in CP hepatocytes with 11.1-fold increase for GPC3 and 4.2-fold increase for CD44, while it remained almost unchanged in CD and NL-Hep (GPC3, NL-Hep 12.7\%,
CP-Hep 70.5\% and CD-Hep 12.3\%; CD44, NL-Hep 7.1\%, CP-Hep 35.4\% and CD-Hep 12.1\%). These results, summarized in Fig. 4, suggest that a higher percentage of hepatocytes from $\mathrm{CP}$ developed HCC-like features progressively in the primary culture. When the cellular localization of these markers was investigated by immunohistochemistry, we observed that GPC3 was broadly distributed in the cytoplasm and membrane of HCC cells with a higher intensity than CP-Hep and CD-Hep (Fig. 5A). Furthermore, we observed that the expression of GPC3 was widely distributed in the cytoplasm of numerous hepatocytes in both $\mathrm{CP}$ and $\mathrm{CD}$. However, a higher number of cells presented positivity for GPC3 in CP-Hep when compared to $\mathrm{CD}-\mathrm{Hep}$. The staining was more robust and presented a prominent filament-like cytoplasmic distribution that was strongly expressed in cellular estroflexions as compared to the less intense and dishomogeneous distribution observed in CD-Hep (Fig. 5).

Activated HSCs in cellular cultures. It has been shown that HSC activation plays a crucial role in supporting inflam- 
A

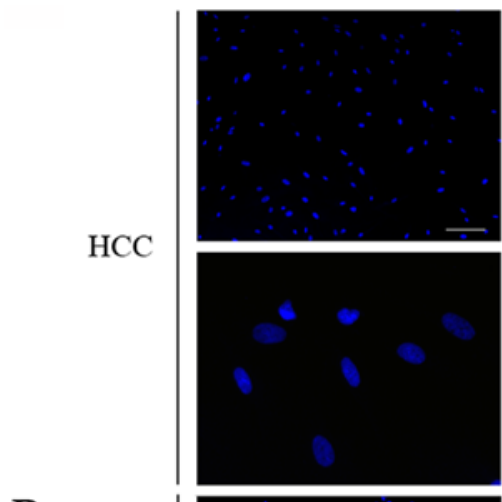

B

C
CD-Hep

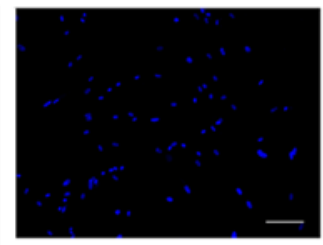

CP-Hep
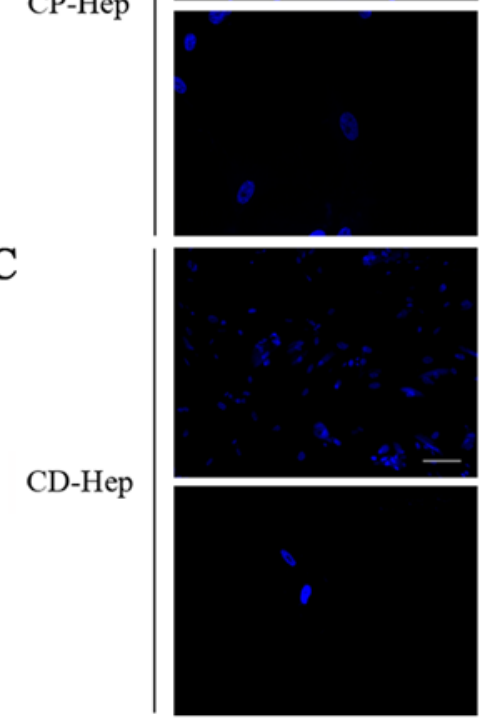

GPC3
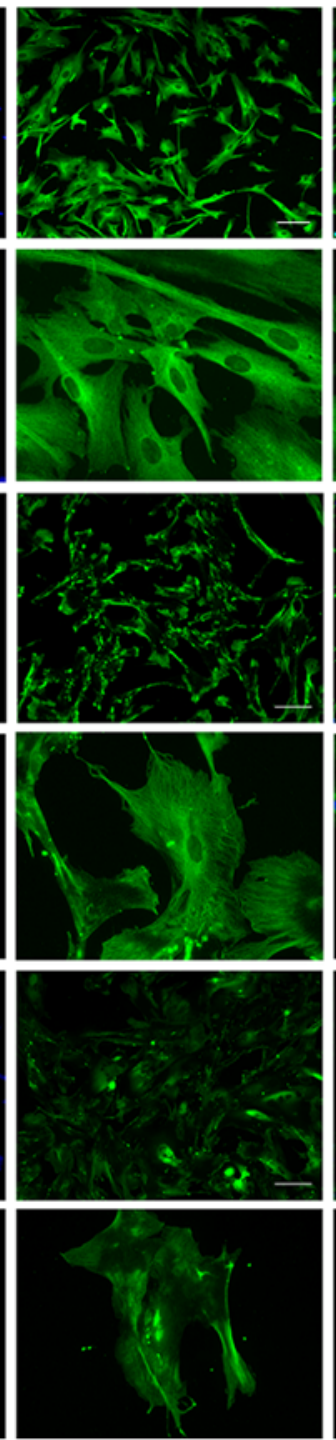

\section{MERGE}
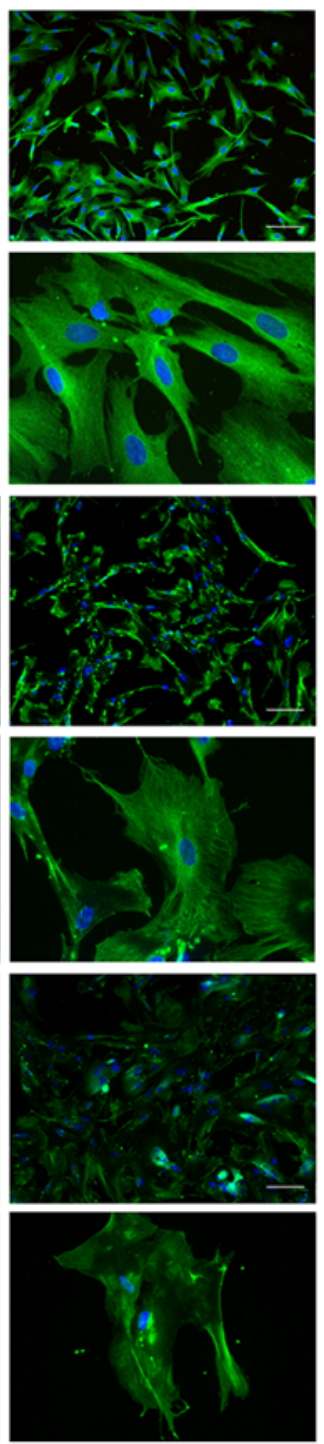

Figure 5. Distribution of GPC3 in CP-Hep, CD-Hep and HCC. (A) In HCC cells GPC3 (GPC3 green; nuclei blue) is localized in cytoplasm and membrane and showed a wide distribution. (B) Immunofluorescence showed increased positivity in CP-Hep and a diffuse distribution with a fine filamentous-like distribution. (C) CD-Hep had a less prominent and heterogeneous distribution (magnification, x100 top, x1000 lower panels of HCC, CP-Hep and CD-Hep). White bar, $100 \mu \mathrm{m}$.

mation and growth of early tumor cells in HCC (26-29). Morphological evaluation of cultured cells supported the presence of HSCs. Presence of activated HSCs in CD and CP cultures was confirmed by $\alpha$-smooth muscle actin ( $\alpha$-SMA) immunofluorescence at 16 weeks of culture (Fig. 6A and B). To exclude the presence of quiescent HSCs we performed Red-oil staining used to identify quiescent hepatic stellate cells (HSCs) detecting retinoic acid inclusions, typical of quiescent stellate cells (26). Using this technique, we confirmed the absence of cytoplasmic retinoic acid inclusions (data not shown). Western blot analysis demonstrated the expression of $\alpha$-SMA (activated HSCs) at time zero in CP, with a significant increase in its expression at 16 weeks, while in $\mathrm{CD} \alpha$-SMA was not present at time zero and only appeared at 16 weeks (Fig. 6C). However, at 16 weeks its expression was markedly higher in CP compared to CD. Overall, these results suggest that the intensity of $\alpha$-SMA positive cells significantly increases in culture, over time, in particular in CP-Hep.

Migration and invasion abilities of $C P$ and $C D$ cells. To evaluate the ability of $\mathrm{CP}$ and $\mathrm{CD}$ cells to penetrate the surrounding tissue, we analyzed their capacity to migrate/invade the extracellular matrix. We evidenced that cells from CP express an ability to migrate to the extracellular matrix at a higher rate than CD-Hep at each time-point tested (mean \pm SD in CP vs. CD, respectively: $90 \pm 8.7$ vs. $9.6 \pm 2.5$ at 48 h, $148 \pm 10$ vs. $46 \pm 7.5$ at $72 \mathrm{~h}$ and $166 \pm 6$ vs. $53.3 \pm 3.5$ at $96 \mathrm{~h}$ from plating; Fig. 7A and $\mathrm{C}$, left panel). Furthermore, cells showing migrating capacity in Transwell migration/invasion assay, formed conglomerates that have been previously described in various cancer types as organoids (30). The organoids observed in these experiments were more numerous and larger in $\mathrm{CP}$ than in $\mathrm{CD}$ samples (mean number of organoids/field $\pm \mathrm{SD}$ in $\mathrm{CP}$ 
A
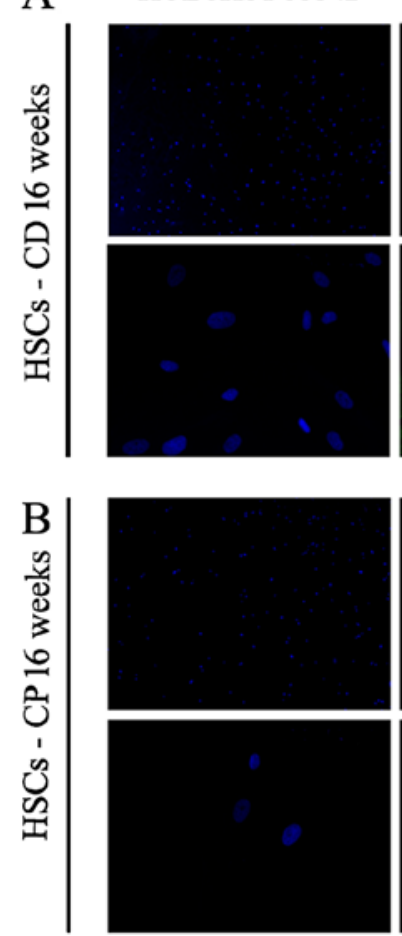

aSMA
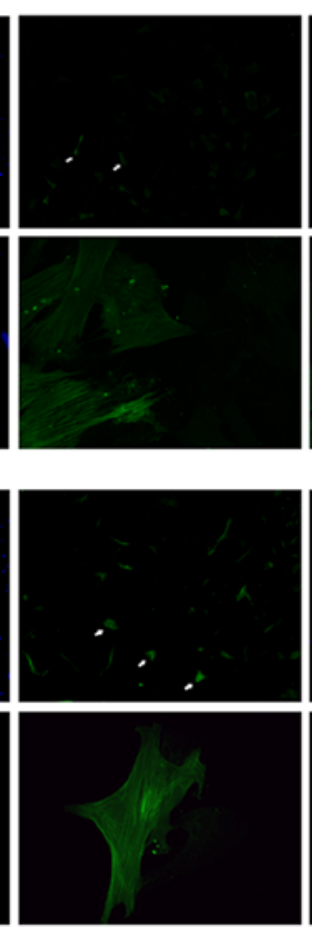

MERGE
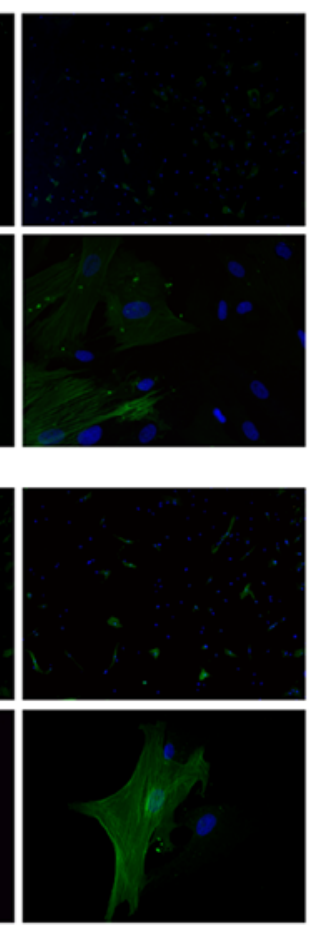

$\mathrm{C}$
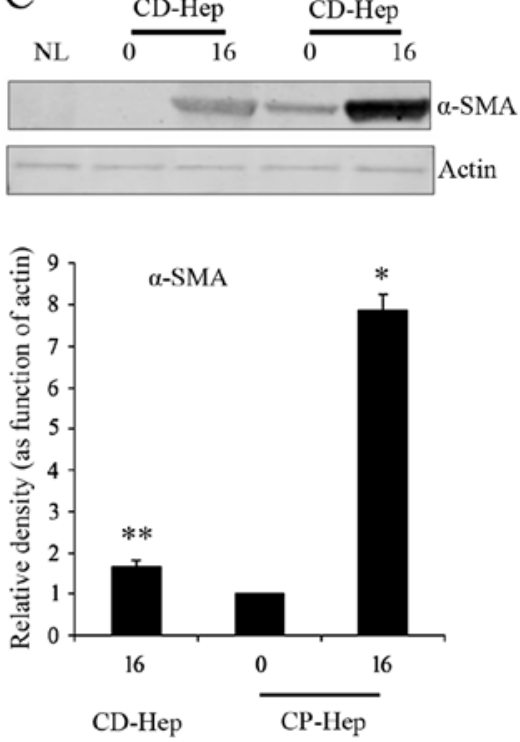

Figure 6. Hepatic stellate cells. Activated HSCs (white arrows) in CD (A) and CP (B) cultures were detected at 16 weeks (antibody anti- $\alpha$-SMA, green; nuclei Hoechst 33342, blue) (A, x40; B, x1000 magnification). (C) Western blot analysis showed presence of expression of $\alpha$-SMA in CP culture at time zero with a marked increment at 16 weeks (mean $\pm \mathrm{SD},{ }^{*} \mathrm{P}=0.001$ ). When $\alpha$-SMA expression was compared at 16 weeks it was also significantly increased in CP compared to $\mathrm{CD}$ culture (mean $\left.\pm \mathrm{SD},{ }^{* *} \mathrm{P}=0.001\right)$. White bar, $500 \mu \mathrm{m}$.

vs. CD respectively: $62.6 \pm 4.5$ vs. $6.3 \pm 2$ at $48 \mathrm{~h}, 65.6 \pm 5.1 \mathrm{vs}$ $37.3 \pm 5$ at $72 \mathrm{~h}$ and $59.6 \pm 1.5$ vs. $35.6 \pm 2.5$ at $96 \mathrm{~h}$ from plating) (Fig. 7B and C).

\section{Discussion}

With the present study we demonstrated for the first time that hepatocytes obtained from proximal areas to HCC present morphologic and neoplastic transformation when cultured in vitro. We observed that while cells from HCC maintained their morphology and unmodified neoplastic characteristics in culture, hepatocytes from $\mathrm{CP}$ showed a progressive morphologic transformation in HCC-like cells, accompanied by expression of specific HCC markers expression and characteristics of invasiveness compared to CD-Hep obtained from the same patients. Thus, increased proximity to HCC seems to be associated with a higher percentage of cells that appear committed to transform in neoplastic cells.

Overall, these data suggest that hepatocytes proximal to $\mathrm{HCC}$ are influenced by a pro-neoplastic microenvironment that determines their morphological and biological transformation in cancer cells. Diverse microenvironments with unique characteristics appear to coexist in the liver influencing hepatocytes differently. We have previously shown that in patients with liver cirrhosis secondary to HCV infection, only a percentage of the entire hepatocyte population (7-20\%) is infected and that these cells are distributed in clusters. In the same study we also demonstrated that HCV foci of infected cells are proximally related to HCC (31). The heterogeneous distribution of the infected areas of the liver during $\mathrm{HCV}$ infection and their relation with $\mathrm{HCC}$ further supports this hypothesis.

The pro-neoplastic transformation observed in the present study was evident starting approximately at ten weeks after initial isolation. The $\mathrm{CP}$ cells appeared to modify their structure from cuboid hepatocytes to an HCC-like morphology. Hence, this modification was associated with a robust increase in the proliferation rate starting at fourteen weeks from isolation. These changes were accompanied by invasive capacity in addition to formation of larger and more numerous organoids, both characteristic of tumorigenicity (32). On the contrary, CD-Hep showed fewer and different morphological changes, reduced proliferation rate and less signs/markers of invasiveness at the same time-points.

The available data in this field are mostly obtained from studies conducted on HCC cell lines (33-35). Immortalized cell lines are able to proliferate but usually do not show modifications of their characteristics over time. We believe that introducing the temporal dynamic component obtained from fresh isolated cells, provides more information on neoplastic transformation as it mimics what occurs in vivo. To confirm that these findings are not secondary to contamination of neoplastic cells or satellite lesions in the liver proximal to HCC, immunohistochemistry, morphologic evaluation and western blot analysis of the cirrhotic tissue used for the cell outgrowth were performed. These confirmed the absence of cancer cells by lack of expression of GPC3 (specific HCC marker) or low expression of Arginase1 and Heppar1 (hepatocyte markers) that are overexpressed in the primary neoplastic lesion of the same patients, comparable to NL. 

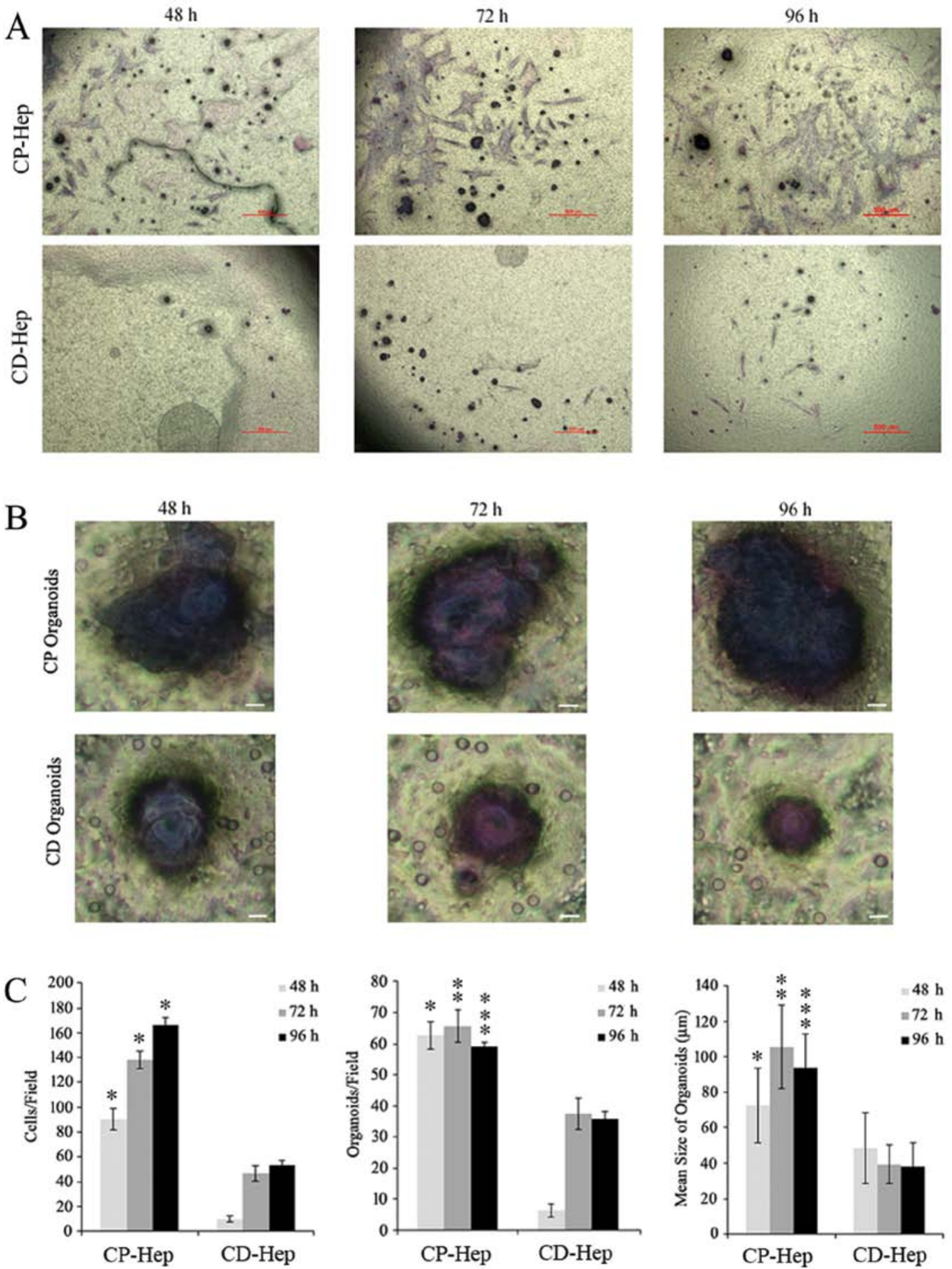

Figure 7. Migration/invasiveness assay. An increased migration capacity in extracellular matrix medium and organoid formation in matrigel at 48,72 and $96 \mathrm{~h}$ was observed in CP-Hep compared to CD-Hep. (A) Larger number of migrated cells was observed in CP-Hep representing higher invasiveness levels (magnification, $x 100$; red bar, $500 \mu \mathrm{m}$ ). (B) Representative size of organoids (white bar, $10 \mu \mathrm{m}$ ). (C) Graphic representation comparing CP and CD-Hep for: number of migrated cells (left graph, mean $\pm \mathrm{SD} ;{ }^{\prime} \mathrm{P}=0.002$ at each time-point); number of organoids/field counted (center graph, mean $\pm \mathrm{SD} ;{ }^{*} \mathrm{P}=0.001$ at $48 \mathrm{~h},{ }^{* *} \mathrm{P}=0.02$ at $72 \mathrm{~h}$ and ${ }^{* * *} \mathrm{P}=0.009$ at $96 \mathrm{~h}$ ); and mean size of organoids (right graph, mean $\pm \mathrm{SD} ;{ }^{*} \mathrm{P}=0.01$ at $48 \mathrm{~h},{ }^{* *} \mathrm{P}=0.001$ at $72 \mathrm{~h}$ and ${ }^{* * *} \mathrm{P}=0.001$ at $96 \mathrm{~h}$ ).

It has been shown that HSC activation plays a crucial role in supporting inflammation and probably the growth of early tumor cells, contributing to the chemo-resistance of HCC (26-29). In the present study, we observed the presence of $\alpha$-SMA positive cells in $\mathrm{CP}$ and $\mathrm{CD}$ cultures suggesting activation of HSCs. Their activity level progressively increased with time as demonstrated by the significant increase of $\alpha$-SMA expression at 16 weeks of incubation.
It is known, that in cancer cell lines, GPC3 is involved in the activation of $\mathrm{Wnt} / \beta$-catenin pathway and promotes cell proliferation of HCC by stimulating the canonical Wnt signaling pathway $(19,20)$. The results here reported show that initially GPC 3 was not expressed by isolated CP-Hep. Then, its presence progressively increased during culture in these cells, suggesting that they were undergoing neoplastic transformation. In fact, only the cells obtained from CP, showed a robust 
increase in protein expression and a striking increase in the percentage of cells expressing GPC3 (from 6.3\% at 4 weeks to $70.5 \%$ at 16 weeks of culture). The emerging role of this glycoprotein, not only as HCC marker but also as molecular target for gene therapy, is arising (21). It has been suggested that the inhibition of translational and post-translational events of GPC 3 could impair the growth and proliferation of HCC (33-35). Moreover, recent research on HCC cell line showed that silencing of GPC3 induces apoptosis of these cancer cells (36).

Expression of CD44 and its isoform CD44v6 are considered markers of liver cancer stem cells $(22,24)$. In the present study, western blot and immunohistochemistry analyses of cultures at time zero revealed very low CD44v6 levels that significantly increased during the dynamic transformation of CP- and CD-Hep. Moreover, flow cytometry revealed that in CP-Hep a progressively larger number of cells express CD44 in culture (from $8.3 \%$ at time zero to $35.4 \%$ at 16 weeks) further strengthening the evidence of neoplastic transformation of these cells.

Clinical observations support that recurrence of $\mathrm{HCC}$ is frequent in the proximity of the primary lesion and is observed usually only a few months after resection or loco-regional treatment (6-8). CP-Hep showed a similar behavior increasing their proliferation rate and expressing HCC characteristics after approximately three months in culture. It is conceivable that these characteristics are secondary to isolation and culture. However, we did not observe these variations in CD-Hep obtained from the same patient and NL-Hep confirming that the different behavior of these cell populations is not related to their culture and manipulation conditions.

Moreover, cells underwent multiple washes and re-plating and culture media was non-inducing without addition of growth factors to reduce differentiation of mesenchymal cells (37). To rule out that the cells obtained at 16 weeks of culture were fibroblast-like mesenchymal cells, a phenotype analysis was performed with specific antibodies confirming that $96 \%$ of these were hepatocytes.

Consequently, we suggest that our findings on CP- and CD-Hep could mimic the neoplastic transformation that these cells would have in vivo in relation to their proximity to a pro-neoplastic microenvironment in the cirrhotic tissue. Furthermore, since we observed similar changes in all patients studied, this phenomenon appears to be consistent.

With the present study, we are first to describe the differences in neoplastic transformation of these cells, creating a new model to investigate tumorigenesis of human hepatocytes obtained from cirrhotic patients. In our opinion this model can be used to investigate molecular mechanisms, identify new markers and evaluate therapeutic interventions for HCC. This new model could provide an important tool for prevention and early intervention, since it can be used to target cells that are not yet cancerous but are in their early phase of transformation in HCC.

\section{References}

1. El-Serag HB: Hepatocellular carcinoma: Recent trends in the United States. Gastroenterology 127 (Suppl 1): S27-S34, 2004.

2. El-Serag HB: Epidemiology of viral hepatitis and hepatocellular carcinoma. Gastroenterology 142: 1264-1273.e1, 2012.
3. Mittal S and El-Serag HB: Epidemiology of hepatocellular carcinoma: Consider the population. J Clin Gastroenterol 47 (Suppl): S2-S6, 2013.

4. Poon RT, Ng IO, Fan ST, Lai EC, Lo CM, Liu CL and Wong J: Clinicopathologic features of long-term survivors and diseasefree survivors after resection of hepatocellular carcinoma: A study of a prospective cohort. J Clin Oncol 19: 3037-3044, 2001.

5. Roayaie S, Obeidat K, Sposito C, Mariani L, Bhoori S, Pellegrinelli A, Labow D, Llovet JM, Schwartz M and Mazzaferro V: Resection of hepatocellular cancer $\leq 2 \mathrm{~cm}$ : Results from two Western centers. Hepatology 57: 1426-1435, 2013.

6. Earl TM and Chapman WC: Hepatocellular carcinoma: Resection versus transplantation. Semin Liver Dis 33: 282-292, 2013.

7. Peng ZW, Lin XJ, Zhang YJ, Liang HH, Guo RP, Shi M and Chen MS: Radiofrequency ablation versus hepatic resection for the treatment of hepatocellular carcinomas $2 \mathrm{~cm}$ or smaller: A retrospective comparative study. Radiology 262: 1022-1033, 2012.

8. Ramakrishna G, Rastogi A, Trehanpati N, Sen B, Khosla R and Sarin SK: From cirrhosis to hepatocellular carcinoma: New molecular insights on inflammation and cellular senescence. Liver Cancer 2: 367-383, 2013.

9. Zhao YJ, Ju Q and Li GC: Tumor markers for hepatocellular carcinoma. Mol Clin Oncol 1: 593-598, 2013.

10. Timek DT, Shi J, Liu H and Lin F: Arginase-1, HepPar-1, and Glypican-3 are the most effective panel of markers in distinguishing hepatocellular carcinoma from metastatic tumor on fine-needle aspiration specimens. Am J Clin Pathol 138: 203-210, 2012.

11. Tomuleasa C, Soritau O, Rus-Ciuca D, Pop T, Todea D, Mosteanu O, Pintea B, Foris V, Susman S, Kacsó G, et al: Isolation and characterization of hepatic cancer cells with stem-like properties from hepatocellular carcinoma. J Gastrointestin Liver Dis 19: 61-67, 2010.

12. Krings G, Ramachandran R, Jain D, Wu TT, Yeh MM, Torbenson $\mathrm{M}$ and Kakar S: Immunohistochemical pitfalls and the importance of glypican 3 and arginase in the diagnosis of scirrhous hepatocellular carcinoma. Mod Pathol 26: 782-791, 2013.

13. Shiran MS, Isa MR, Sherina MS, Rampal L, Hairuszah I and Sabariah AR: The utility of hepatocyte paraffin 1 antibody in the immunohistological distinction of hepatocellular carcinoma from cholangiocarcinoma and metastatic carcinoma. Malays $\mathbf{J}$ Pathol 28: 87-92, 2006.

14. Pfeiffer E, Kegel V, Zeilinger K, Hengstler JG, Nüssler AK, Seehofer D and Damm G: Featured Article: Isolation, characterization, and cultivation of human hepatocytes and non-parenchymal liver cells. Exp Biol Med (Maywood) 240: 645-656, 2015.

15. Ihara A, Koizumi H, Hashizume R and Uchikoshi T: Expression of epithelial cadherin and alpha- and beta-catenins in nontumoral livers and hepatocellular carcinomas. Hepatology 23: 1441-1447, 1996.

16. Wands JR and Kim M: WNT/ $\beta$-catenin signaling and hepatocellular carcinoma. Hepatology 60: 452-454, 2014.

17. Ho M and Kim H: Glypican-3: A new target for cancer immunotherapy. Eur J Cancer 47: 333-338, 2011.

18. The International Consensus Group for Hepatocellular Neoplasia: Pathologic diagnosis of early hepatocellular carcinoma: A report of the international consensus group for hepatocellular neoplasia. Hepatology 49: 658-664, 2009.

19. Capurro M, Martin T, Shi W and Filmus J: Glypican-3 binds to Frizzled and plays a direct role in the stimulation of canonical Wnt signaling. J Cell Sci 127: 1565-1575, 2014.

20. Capurro MI, Xiang YY, Lobe C and Filmus J: Glypican-3 promotes the growth of hepatocellular carcinoma by stimulating canonical Wnt signaling. Cancer Res 65: 6245-6254, 2005.

21. Yao M, Wang L, Dong Z, Qian Q, Shi Y, Yu D, Wang S, Zheng W and Yao D: Glypican-3 as an emerging molecular target for hepatocellular carcinoma gene therapy. Tumour Biol 35: 5857-5868, 2014.

22. Zhu Z, Hao X, Yan M, Yao M, Ge C, Gu J and Li J: Cancer stem/progenitor cells are highly enriched in $\mathrm{CD} 133^{+} \mathrm{CD} 44^{+}$ population in hepatocellular carcinoma. Int J Cancer 126: 2067-2078, 2010.

23. Endo K and Terada T: Protein expression of CD44 (standard and variant isoforms) in hepatocellular carcinoma: Relationships with tumor grade, clinicopathologic parameters, p53 expression, and patient survival. J Hepatol 32: 78-84, 2000. 
24. Afify A, Purnell P and Nguyen L: Role of CD44s and CD44v6 on human breast cancer cell adhesion, migration, and invasion. Exp Mol Pathol 86: 95-100, 2009.

25. Xie Z, Choong PF, Poon LF, Zhou J, Khng J, Jasinghe VJ, Palaniyandi $S$ and Chen CS: Inhibition of CD44 expression in hepatocellular carcinoma cells enhances apoptosis, chemosensitivity, and reduces tumorigenesis and invasion. Cancer Chemother Pharmacol 62: 949-957, 2008.

26. Blaner WS,O'Byrne SM, Wongsiriroj N,Kluwe J,D'Ambrosio DM, Jiang H, Schwabe RF, Hillman EM, Piantedosi R and Libien J: Hepatic stellate cell lipid droplets: A specialized lipid droplet for retinoid storage. Biochim Biophys Acta 1791: 467-473, 2009.

27. Amann T, Bataille F, Spruss T, Mühlbauer M, Gäbele E, Schölmerich J, Kiefer P, Bosserhoff AK and Hellerbrand C: Activated hepatic stellate cells promote tumorigenicity of hepatocellular carcinoma. Cancer Sci 100: 646-653, 2009.

28. Yu G, Jing Y, Kou X, Ye F, Gao L, Fan Q, Yang Y, Zhao Q, Li R, Wu M, et al: Hepatic stellate cells secreted hepatocyte growth factor contributes to the chemoresistance of hepatocellular carcinoma. PLoS One 8: e73312, 2013.

29. Geng ZM, Li QH, Li WZ, Zheng JB and Shah V: Activated human hepatic stellate cells promote growth of human hepatocellular carcinoma in a subcutaneous xenograft nude mouse model. Cell Biochem Biophys 70: 337-347, 2014

30. Gao D, Vela I, Sboner A, Iaquinta PJ, Karthaus WR, Gopalan A Dowling C, Wanjala JN, Undvall EA, Arora VK, et al: Organoid cultures derived from patients with advanced prostate cancer. Cell 159: 176-187, 2014
31. Liang Y, Shilagard T, Xiao SY, Snyder N, Lau D, Cicalese L, Weiss $H$, Vargas $G$ and Lemon SM: Visualizing hepatitis $C$ virus infections in human liver by two-photon microscopy. Gastroenterology 137: 1448-1458, 2009.

32. Sachs $N$ and Clevers H: Organoid cultures for the analysis of cancer phenotypes. Curr Opin Genet Dev 24: 68-73, 2014.

33. Zittermann SI, Capurro MI, Shi W and Filmus J: Soluble glypican 3 inhibits the growth of hepatocellular carcinoma in vitro and in vivo. Int J Cancer 126: 1291-1301, 2010.

34. Sun CK, Chua MS, He J and So SK: Suppression of glypican 3 inhibits growth of hepatocellular carcinoma cells through up-regulation of TGF- $\beta 2$. Neoplasia 13: 735-747, 2011.

35. Gao W, Kim H, Feng M, Phung Y, Xavier CP, Rubin JS and Ho M: Inactivation of Wnt signaling by a human antibody that recognizes the heparan sulfate chains of glypican-3 for liver cancer therapy. Hepatology 60: 576-587, 2014.

36. Liu S, Li Y, Chen W, Zheng P, Liu T, He W, Zhang J and Zeng X: Silencing glypican-3 expression induces apoptosis in human hepatocellular carcinoma cells. Biochem Biophys Res Commun 419: 656-661, 2012.

37. Stock P, Brückner S, Ebensing S, Hempel M, Dollinger MM and Christ B: The generation of hepatocytes from mesenchymal stem cells and engraftment into murine liver. Nat Protoc 5: 617-627, 2010 . 